\title{
SPECTROPHOTOMETRIC DETERMINATION OF REDUCING SUGAR IN WINES EMPLOYING IN-LINE DIALYSIS AND A MULTICOMMUTED FLOW ANALYSIS APPROACH
}

\author{
PAULO A. B. DA SILVA ${ }^{1,2}$, GUSTAVO C. S. DE SOUZA'2, ANA PAULA S. PAIM ${ }^{2}$ ANDRÉ F. LAVORANTE *
}

${ }^{1}$ Instituto Federal de Alagoas, Campus Coruripe, 57035 Maceió, Al, Brasil,

${ }^{2}$ Departamento de Química Fundamental, Universidade Federal de Pernambuco, Av. Prof. Luiz Freire, s/n, Cidade Universitária, 50740-540 Recife, PE, Brasil, ${ }^{3}$ Departamento de Química, Universidade Federal Rural de Pernambuco, Rua Dom Manuel de Medeiros, s/n, Dois Irmão, 52171-900 Recife, PE, Brasil

\section{ABSTRACT}

A multicommuted flow procedure for the spectrophotometric determination of reducing sugars in wine has been developed. A dialysis unit was incorporated in the system to minimize matrix interferences and eliminate the colored compounds of the wine. The oxidation-reduction reaction in an alkaline medium between reducing sugars and the $\mathrm{Cu}^{2+}$-Neocuproine complex was employed. The compound formed was monitored at $460 \mathrm{~nm}$. In the proposed procedure, there was a linear response between 0.25 and $4.0 \mathrm{~g} \mathrm{~L}^{-1}$ reducing sugars $(\mathrm{y}=(0.36 \pm 0.02)+(0.31 \pm 0.01) * \mathrm{x}, \mathrm{R}=0.9975, \mathrm{n}=6)$, a coefficient of variance of $2.6 \%$ for a reducing sugar solution of $2.0 \mathrm{~g} \mathrm{~L}^{-1}(\mathrm{n}=7)$, a limit of detection estimated at $0.03 \mathrm{~g} \mathrm{~L}^{-1}$, reagent consumption per determination of $0.330,0.128$ and $0.160 \mathrm{mg}$ for neocuproine, $\mathrm{CuSO}_{4}$ and $\mathrm{NaOH}$, respectively. A sampling throughput of 45 determinations per hour was achieved. The proposed system was applied to wine samples and comparing the results with an AOAC official method no significant difference at a $95 \%$ confidence level.

Keywords: Dialysis; Flow injection analysis; Multicommutation; Reducing sugar; Wine.

\section{INTRODUCTION}

In the course of the history of humanity, the use of carbohydrates to give taste to foods and beverages or, as a substrate to fermentation, has been a common practice ${ }^{1}$. Glucose and fructose (monosaccharides) are sugars, members of the carbohydrate family, that contain an aldehydic and ketonic group, respectively ${ }^{2}$. In wine, beer and juice production, the quantification of the reducing sugars (RS) is essential. Specifically, the level of RS determines the degree of alcohol in wines ${ }^{3}$. The concentration of glucose, in $\mathrm{g} \mathrm{L}^{-1}$, is used for the commercial classification of wines: dry wines, $<5$; semi-sweet, 5 to 25 ; sweet whether fortified or not, 25 to 125.0 ; and musts and mistelles, $>125^{4}$.

The determination of RS is frequently performed in the wine industry as an important parameter for controlling production and the fermentation process. The determination of the reducing sugars in wines is also used for routine quality control and to verify if the wine contains the legal or commercial reducing sugar content required for a certain wine type. The batch analytical methods to determine RS involves previous steps of sample preparation such as sample clarification and distillation in reflux to remove alcohol in the wine. This procedure is slow and generates a large residue volume. The spectrophotometric batch assay for the total reducing sugars determination based on the reduction of $\mathrm{Cu}$ (II) to $\mathrm{Cu}$ (I) with reducing sugars in alkaline medium in the presence of neocuproine in various food products was proposed by Baskan et al. (2016) $)^{5}$. The interference effect of phenolic compounds in samples was eliminated by a solid phase extraction (SPE) clean-up process. Therefore, are demanding in terms of the chemicals consumed, involve several steps and, thus, much manual work, labor-intensive and time-consuming.

The last decades have demonstrated the important role played by methodologies based on flow analysis for the automation and development of methods based on wet chemistry analysis ${ }^{6}$. These methodologies have been well reported, such as automation tools for handling solutions and pre-treatment of samples ${ }^{7}$. Examples include the coupling of interfaces in flow analysis for pre-treatment of sample such as, gas-liquid (gas diffusion, distillation and hydride generation), liquid-liquid (extraction and dialysis) and liquid-solid (ion exchange, adsorption, precipitation, dissolution and stripping $)^{8-14}$

The indirect determination of RS in of wine employing the classical Fehling's reaction and flow injection coupled to atomic absorption spectrometry (AAS) was reported by Yebra et al. (1993) ${ }^{15}$. The copper(I) oxide is precipitated by injecting the Fehling's solutions into the wine carrier. When Fehling's solutions were injected into the sample stream, there is a decrease in the measured signal AAS owing to $\mathrm{Cu}(\mathrm{I})$ precipitate. The difference between the signals yielded the amount of precipitated copper, which was proportional to the reducing sugar concentration in the sample. The sampling frequency of the method is 12 min per analysis, due to interruption of the flow for $10 \mathrm{~min}$ resulting in a high cost of analysis, because the gas consumption excessive for maintaining the AAS connected.

The biosensors and biosensing flow systems for determination of reducing sugars in wines are many varied, and they may be based on amperometry, potenciometry, photometry and fluorimetric detection ${ }^{16}$. However, the methods depend upon the construction of electrode chemically modified or immobilization of material and biomaterial (enzymes) for the molecular recognition.

A procedure based on sequential injection analysis (SIA) with dialysis unit incorporated was described for to spectrophotometric determination of reducing sugars in wine employing reaction of copper (I) with neocuproine, after reduction of copper (II) to copper (I) by reducing sugars. The determination of reducing sugars in two concentration ranges, from 2 to 25 and from 20 to $140 \mathrm{~g} \mathrm{~L}^{-1}$ was applied, yielding sampling-rate of the $14-18$ samples per hour ${ }^{17}$.

Conceptually, the multicommuted flow injection analysis (MCFIA) process includes discretely computer-operated devices strategically positioned in a manifold ${ }^{18}$. The control of these devices by software allows the insertion of an aliquot solution, as well as enablement of individual variable flow rates. Different systems have been proposed for many different types of analytes in different matrices employing MCFIA ${ }^{19-21}$. Other approach uses of the MCFIA have been with micro-pumps, devices that produce a pulsed flow, thus increasing the interactions between the solutions in the MCFIA system ${ }^{6}$. Furthermore, environmentally friendly systems and highly sensitive analyses have been achieved ${ }^{9,12,22}$. Additional advantages of the micro-pumps in a multicommutation system include portability, low energy requirements and the ability to minimize volume reagent consumed and consequently waste generation $^{23,24}$.

The association of interface liquid-liquid (extraction or diffusion) with MCFIA has been employed for the determination of molybdenum ${ }^{25}$ and $\mathrm{lead}^{26}$ in plants, copper in water samples ${ }^{27}$, anti-hypertensive diltiazem in pharmaceutical samples ${ }^{28}$, tartaric acid and potassium in Port and table wines ${ }^{29}$ and sulfur dioxide in wines ${ }^{30}$.

A MCFIA procedure for simultaneous spectrophotometric determination of nonstructural carbohydrates and reducing sugar in forage materials was proposed by Tumang et al. $(2003)^{31}$. The determination of both analytes was based on the neocuproine method after acid hydrolysis of nonstructural carbohydrates. In the proposed system, ease of operation and robustness were observed, keeping the intrinsic characteristics of the MCFIA.

A multicommutation flow procedure using $\mathrm{Cu}-4,4$ '-dipyridyl coordination as the phase-solid reagent for to spectrophotometric determination reducing sugar in juice and coconut water samples was proposed by Leotério et al $(2015)^{32}$. In the procedure, a linear range from 1.0 to $20.0 \mathrm{~g} \mathrm{~L}-1$, detection at $0.23 \mathrm{~g} \mathrm{~L}-1$ and a sampling throughput of 75 determinations per hour were achieved. The system enabled the analysis with simplicity and a significant economy of the reagent and of the waste generation.

In this work, a multicommuted flow procedure based on-line dialysis coupled to micro-pumps for the determination of RS in wine was developed. The dialysis membrane followed by spectrophotometric detection has the advantage of eliminating potential interferences, mainly the color (phenolic compounds) of the wine, requires no sample pretreatment, reducing the amount of reagents consumed, without sacrificing the main analytical properties. 


\section{EXPERIMENTAL}

\section{Reagents and chemicals}

All chemical reagents were of analytical grade and used as purchased without additional purification and all solutions were prepared with deionized water (resistivity $>18 \mathrm{M} \Omega \mathrm{cm}^{-1}$ ) from a Milli-Q system (Millipore Inc., Bedford, MA)

A $100 \mathrm{~g} \mathrm{~L}^{-1} \mathrm{RS}$ stock solution, what consisted of a mixture of fructose $(60 \%$, w/w) (Sigma-Aldrich, $>99.5 \%)$ and glucose $(40 \%, w / w)$ (SigmaAldrich, $>99.5 \%$ ), was prepared by dissolving monosaccharides in $25 \mathrm{~mL}$ of water. Working standard solutions with concentrations within the range of 0.25 to $4.0 \mathrm{~g} \mathrm{~L}^{-1}$, containing $12 \%(\mathrm{v} / \mathrm{v})$ of ethanol were prepared daily by dilution of the stock solution.

A $0.1 \mathrm{~mol} \mathrm{~L}^{-1}\left[(\mathrm{Cu}-\mathrm{Neo})_{2}\right]^{2+}$ solution was prepared daily by dissolving $1.041 \mathrm{~g}$ of neocuproine, $\mathrm{C}_{14} \mathrm{H}_{12} \mathrm{~N}_{2}$ (2,9-dimethyl-1,10-phenanthroline, SigmaAldrich, $>99.5 \%$ ) in $5 \mathrm{~mL}$ of ethanol. This was added to an aqueous solution containing $0.4 \mathrm{~g}$ of copper sulphate pentahydrate (Sigma-Aldrich, 99\%) and the mixture was diluted to $50 \mathrm{~mL}$ with water. The working solutions were obtained by diluting a stock solution into concentrations of $0.0025,0.005,0.01$, 0.015 and $0.02 \mathrm{~mol} \mathrm{~L}^{-1}$.

A $1.0 \mathrm{~mol} \mathrm{~L}^{-1}$ sodium hydroxide stock solution was prepared by dissolving $4.0 \mathrm{~g}$ of $\mathrm{NaOH}$ (Vetec) in $100 \mathrm{~mL}$ water. The working solutions were obtained by diluting a stock solution into concentrations between 0.005 and $0.3 \mathrm{~mol} \mathrm{~L}^{-1}$.

The wine samples of different types were purchased at local markets. Some wine samples were analyzed after appropriate dilution with water.

\section{Apparatus}

The equipment setup included an Ocean Optics USB-4000-UV-VIS spectrophotometer, equipped with optical fiber cables of $50 \mu \mathrm{m}$ internal diameter to transport the radiation, a tungsten-halogen lamp, a flow cell with a $10 \mathrm{~mm}$ optical path (Hellma, Plainview, NY, USA; $80 \mu \mathrm{L}$ internal volume), solenoid micro-pumps (Biochem Valve ${ }^{\mathrm{TM}}$ Inc., Boonton, NJ, USA) of $4 \mu \mathrm{L}$ ( $\mathrm{P}_{1}$, $\mathrm{P}_{2}$ and $\left.\mathrm{P}_{3}\right)$ and $10 \mu \mathrm{L}\left(\mathrm{P}_{4}\right.$ and $\left.\mathrm{P}_{5}\right)$ nominal volumes, reaction coils and flow lines made of polyethylene tubing $(0.8 \mathrm{~mm}$ i.d.), acrylic laboratory-made joints used as confluences, a dialysis unit and a thermostatic bath (QUIMIS ${ }^{\circledR}$ ).

The dialysis unit consisted of two Perspex blocks that were fixed to each other by four screws. A membrane cellulose nitrate (Sartorius Stedim Biotech, Germany) with a pore size of $0.45 \mu \mathrm{m}$ was placed between the two blocks, and replaced weekly.

For the control of the micro-pumps and data acquisition, software in language Lab View $8.5^{\circledR}$ was developed. A homemade electronic interface assembled using an ULN2803 integrated circuit connected to an interface (USB-6009, National Instruments, USA) was employed to drive the micropumps. The signal generated by the spectrophotometer was monitored through the computer's USB 2.0 port. The frequencies of the micro-pumps were maintained at $5 \mathrm{~Hz}$, which consisted in equal time intervals switched $\mathrm{ON}$ or OFF $(0.1 \mathrm{~s} / 0.1 \mathrm{~s})$.

\section{Flow system and procedure}

The design of the flow system was based on multicommutation, and the flow diagram is shown in Figure 1. The flow system was designed with five solenoid micro-pumps $\left(\mathrm{P}_{1}\right.$ to $\left.\mathrm{P}_{5}\right)$ which were assembled to allow the handling of the solutions for the detection. The micro-pumps $\mathrm{P}_{1}, \mathrm{P}_{2}$, and $\mathrm{P}_{3}$ were responsible for the introduction of the sample and reagent solutions, respectively, while $\mathrm{P}_{4}$ and $\mathrm{P}_{5}$ were used for the introduction of the carrier. In this configuration, all the micro-pumps are switched OFF, thus no solution is flowing through the analytical path.

Initially, the system was activated to fill the flow lines with solutions, which was done following the sequence indicated in Table 1 (steps $a$ to $e$ ).

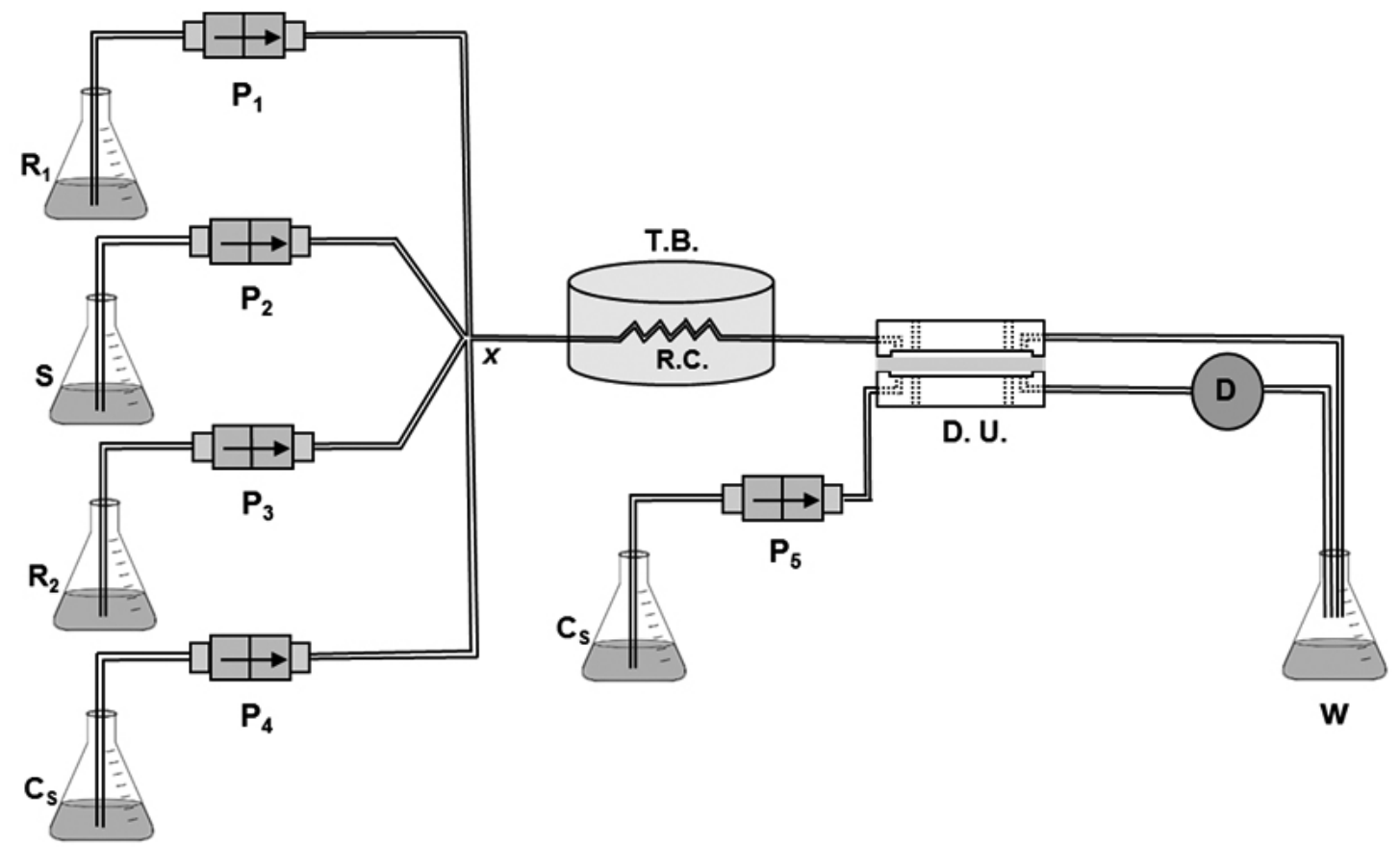

Figure 1. Flow diagram of the multicommuted flow system. $\mathrm{S}=$ sample; $\mathrm{Cs}=$ carrier solution, water; $\mathrm{R}_{1}=0.050 \mathrm{~mol} \mathrm{~L}^{-1}$ $\mathrm{NaOH} ; \mathrm{R}_{2}=0.010$ mol L-1 $\left[(\mathrm{Cu}-\mathrm{Neo})_{2}\right]^{2+}$ complex; $\mathrm{P}_{1}, \mathrm{P}_{2} \mathrm{P}_{3} \mathrm{P}_{4} \mathrm{P}_{5}=$ solenoid micro-pumps; $x=$ joint devices machined in acrylic; R.C. $=$ Polyethylene reactor coils $(100.0 \mathrm{~cm}$ length, $0.8 \mathrm{~mm}$ i.d. $) ;$ T.B. $=$ thermostatic bath; D.U. $=$ dialysis unit. $\mathrm{D}=$ spectrophotometric detector at $480 \mathrm{~nm} ; \mathrm{W}=$ waste vessel.

For spectrometer calibration (Table 1, step f), the dark (the tungstenhalogen lamp off) and reference (the tungsten-halogen lamp on) readings were performed. To obtain the relation of absorbance (A) versus time was used the equation $\mathrm{A}=-\log \left(\left(\mathrm{I}_{2}-\mathrm{I}_{0}\right) /\left(\left(\mathrm{I}_{1}-\mathrm{I}_{0}\right)\right)\right.$, where $\mathrm{I}_{0}=$ intensity in the dark, $\mathrm{I}_{1}=$ intensity with the carrier solution and $\mathrm{I}_{2}=$ intensity with sample solution. This equation made it possible to calculate the relative absorbance of the sample solution. The absorbance data generated were saved as a file.LVM, which was recognized by the graphic editor program. 
Table 1: Switching steps of solenoid micro-pump for determination of reducing sugar.

\begin{tabular}{|c|c|c|c|c|c|c|c|c|}
\hline Step & Event & $P_{1}$ & $\mathbf{P}_{2}$ & $\mathbf{P}_{3}$ & $\mathbf{P}_{4}$ & $P_{5}$ & Pulses & Cycles \\
\hline $\mathrm{a}$ & \multirow{5}{*}{ Flow lines filling } & $0 / 1$ & 0 & 0 & 0 & 0 & 50 & - \\
\hline $\mathrm{b}$ & & 0 & $0 / 1$ & 0 & 0 & 0 & 50 & - \\
\hline $\mathrm{c}$ & & 0 & 0 & $0 / 1$ & 0 & 0 & 50 & - \\
\hline $\mathrm{d}$ & & 0 & 0 & 0 & $0 / 1$ & 0 & 50 & - \\
\hline e & & 0 & 0 & 0 & 0 & $0 / 1$ & 50 & - \\
\hline $\mathrm{f}$ & Spectrophotometer calibration & 0 & 0 & 0 & 0 & 0 & 0 & - \\
\hline 1 & $\mathrm{NaOH}$ insertion & $0 / 1$ & 0 & 0 & 0 & 0 & 8 & \multirow{3}{*}{10} \\
\hline 2 & Sample insertion & 0 & $0 / 1$ & 0 & 0 & 0 & 4 & \\
\hline 3 & {$\left[(\mathrm{Cu}-\mathrm{Neo})_{2}\right]^{2+}$ complex insertion } & 0 & 0 & $0 / 1$ & 0 & 0 & 16 & \\
\hline 4 & Transport, detection and washing & 0 & 0 & 0 & $0 / 1$ & $0 / 1$ & 100 & - \\
\hline
\end{tabular}

Numbers 0 and 1 in the columns indicate that was switched OFF or ON, respectively. This case, $0.1 \mathrm{~s} / 0.1 \mathrm{~s}(\mathrm{ON} / \mathrm{OFF})$

The flow procedure for the determination of reducing sugars in wine sample was performed following the protocol sequence presented in Table 1 (steps 1 - 4). The analytical cycle started with introduction of sodium hydroxide $\left(\mathrm{R}_{1}\right)$, sample $(\mathrm{S})$ and $\left[(\mathrm{Cu}-\mathrm{Neo})_{2}\right]^{2+}$ complex $\left(\mathrm{R}_{2}\right)$, through the switching of micro-pumps $\mathrm{P}_{1}, \mathrm{P}_{2}$ and $\mathrm{P}_{3}$, respectively (steps 1,2 and 3). The binary sampling pattern concept was adopted ${ }^{28}$. Micro-pumps $\mathrm{P}_{1}, \mathrm{P}_{2}$ and $\mathrm{P}_{3}$, were switched ON/OFF sequentially. Thus, a total volume of $0.32 \mathrm{~mL} \mathrm{NaOH}$ solution (corresponding to 10 cycles of 8 pulses of micro-pump $\mathrm{P}_{1}$ ), $0.16 \mathrm{~mL}$ sample solution (10 cycles of 4 pulses of micro-pump $\mathrm{P}_{2}$ ) and $0.64 \mathrm{~mL}[(\mathrm{Cu}-$ $\left.\mathrm{Neo})_{2}\right]^{2+}$ complex solution (10 cycles of 16 pulses of micro-pumps $\mathrm{P}_{3}$ ) were employed for each measurement.

After the sampling step, micro-pumps $\mathrm{P}_{4}$ and $\mathrm{P}_{5}$ were switched $\mathrm{ON}$ / OFF simultaneously, and $\mathrm{P}_{4}$ carried the sample zone to the reaction coil (RC) where it was put in a thermostat bath. The reaction coil was linked the top of the dialysis unit. In the $\mathrm{RC}$, the oxidation-reduction reaction in an alkaline medium, between the $\left[(\mathrm{Cu}-\mathrm{NeO})_{2}\right]^{2+}$ and reducing sugars occurred. The $[(\mathrm{Cu}-$ $\left.\mathrm{Neo})_{2}\right]^{+}$complex liquid formed diffused to below the dialysis unit and was transported, by the $\mathrm{P}_{5}$, to the detector (at $460 \mathrm{~nm}$ ) with the carrier solution. While the analytical signal was processing, the carrier solution was transported to the waste and the analytical run was completed. For the exchange of the sample solution, steps $b$ and $d$ were carried out, (Table 1 ), sequentially and with the same four steps $(1-4)$ as presented in Table 1 .

The determination of the RS was based on a redox reaction with $\mathrm{Cu}^{2+}$ in an alkaline medium. For the optimization of the reaction, a study was made ranging the concentrations of the $\mathrm{NaOH}$ of 0.005 at $0.3 \mathrm{~mol} \mathrm{~L}^{-1}$ and $[(\mathrm{Cu}-$ $\left.\mathrm{Neo})_{2}\right]^{2+}$ of 0.0025 at $0.02 \mathrm{~mol} \mathrm{~L}^{-1}$. For this study, the concentration of reference solution was fixed as $1.0 \mathrm{~g} \mathrm{~L}^{-1}$ of reducing sugar, a volumetric ratio of $1: 1: 1$ (NaOH:RS:[(Cu-Neo) $\left.)_{2}\right]^{2+}$ ) with 10 pulses for each solution and 10 sampling cycles, maintaining the temperature at $65^{\circ} \mathrm{C}$. Subsequently, the influence of temperature with ranges between 50 and $100{ }^{\circ} \mathrm{C}$ was studied. The volumetric ratio of the $\mathrm{NaOH}, \mathrm{RS}$ and $\left[(\mathrm{Cu}-\mathrm{Neo})_{2}\right]^{2+}$ complex solutions was established by varying the switching sequential of the micro-pumps $\mathrm{P}_{1}, \mathrm{P}_{2}$ and $\mathrm{P}_{3}$. Therefore, the number of pulses of the micro-pumps $\mathrm{P}_{1}, \mathrm{P}_{2}$ and $\mathrm{P}_{3}$ varied between 4 at 18 , corresponding to variation of 160 at $720 \mu \mathrm{L}$, respectively, by sampling cycles presented in Tables 2, 3 and 4. For those studies the number of sampling cycles was set at 10 cycles and analytical curve was constructed by varying the concentration of RS between 0.25 and $4.0 \mathrm{~g} \mathrm{~L}^{-1}$ for each variation in the volumes studied. Following this, a study of the sampling cycles, varying between 2 and 20, was carried out. For all experiments proposed, the reactor length and flow rate was set at $100 \mathrm{~cm}$, and $2.0 \mathrm{~mL} \mathrm{~L}^{-1}$, respectively.

Once the best operating conditions were established, eleven samples of wine were analyzed in order to prove the usefulness of the proposed system.

\section{Reference method}

The results obtained by the procedure proposed were compared with those obtained with the method recommended by AOAC International for RS determination in wines ${ }^{33}$. The recommended procedure consisted of a reaction between reducing sugars with cupric ions in Fehling's solution, reducing them to cuprous ions under the action of heat in an alkaline medium. By reacting with cupric ions, sugars undergo oxidation, while the $\mathrm{Cu}^{2+}$ is reduced to $\mathrm{Cu}^{+}$, forming a red precipitate of cuprous oxide.

\section{RESULTS AND DISCUSSION}

\section{General aspects}

The theoretical principles of crossflow filtration are based by Fick's law of diffusion ${ }^{34}$, where the migration of suspended solids/macromolecules occurs in the sense of filtration surface. The design of a successful crossflow system relies on efficient choice of the membrane type. The physical aspects of the membrane of the relative size exclusion such as type of polymer, the geometry and pore size of the membrane were integral part of process optimization ${ }^{35}$ (Pawliszyn, 2012). In preliminary study were tested different membranes types based on their composition and pore size, including cellulose acetate, cellulose nitrate, polyacrilonitrile, polytetrafluoroethylene (Teflon ${ }^{\circledR}$ ) and polyvinylidiene fluoride with different porosities. The cellulose nitrate membrane with a pore size of $0.45 \mu \mathrm{m}$ showed more significant response regarding the percentage recovery being selected to develop the proposed system.

The principle of the method can be expressed by the following chemical equation $(1)^{36}$

$\left[(\mathrm{Cu}-\mathrm{NeO})_{2}\right]^{2+}+\mathrm{C}_{6} \mathrm{H}_{12} \mathrm{O}_{6} \underset{\mathrm{NaOH}}{\longrightarrow}\left[(\mathrm{Cu}-\mathrm{NeO})_{2}\right]^{+}+\mathrm{C}_{5} \mathrm{H}_{11} \mathrm{O}_{5} \mathrm{COOH}$

Job's method was employed to study the stoichiometric ratio ${ }^{37}$, between $\mathrm{Cu}^{2+}$ and neocuproine. The solutions were prepared with an equal molar concentration and the volumetric ratio from 1:9 to $9: 1(\mathrm{v} / \mathrm{v})$ was varied. In this study, both solutions were prepared with $0.01 \mathrm{~mol} \mathrm{~L}^{-1}$. The spectrum wavelength ranging from 400 to $700 \mathrm{~nm}$ and the maximum absorption was obtained at $460 \mathrm{~nm}$. The best stoichiometric ratio value estimated between $\mathrm{Cu}^{2+}$ and neocuproine was $1: 2(\mathrm{v} / \mathrm{v})$.

Chemical and hydrodynamic parameters of the proposed procedure were studied by the univariate method, considering with pre-established initial conditions, such as concentrations of $1.0 \mathrm{~g} \mathrm{~L}^{-1}, 0.01 \mathrm{~mol} \mathrm{~L}^{-1}$ and $0.01 \mathrm{~mol} \mathrm{~L}^{-1}$ for the RS reference, $\mathrm{NaOH}$ and $\left[(\mathrm{Cu}-\mathrm{Neo})_{2}\right]^{2+}$ solutions, respectively; $65^{\circ} \mathrm{C}$ for the thermostatic bath; volumetric ratio of $1: 1: 1(\mathrm{v} / \mathrm{v})$; with 10 pulses for each solution and 10 sampling cycles, as the starting point. In preliminary studies, the reactor length has not had significant influence on the development of multicommuted system proposed, being the best condition initially established was at steady state condition. In this way, the reactor length was set at $100 \mathrm{~cm}$.

\section{System optimization}

\section{Effect of the $\mathrm{NaOH}$ and $\left[(\mathrm{Cu}-\mathrm{Neo})_{2}\right]^{2+}$ concentration}

The effect of the $\left[(\mathrm{Cu}-\mathrm{Neo})_{2}\right]^{2+}$ and $\mathrm{NaOH}$ concentration on the analytical response was investigated maintaining the parameters cited above and using a $1.0 \mathrm{~g} \mathrm{~L}^{-1} \mathrm{RS}$ reference solution. The concentration of the $\mathrm{NaOH}$ and $[(\mathrm{Cu}-$ $\left.\mathrm{Neo})_{2}\right]^{2+}$ varied from 0.005 to $0.30 \mathrm{~mol} \mathrm{~L}^{-1}$, and from 0.0025 to $0.02 \mathrm{~mol} \mathrm{~L}^{-1}$, respectively as shown in Figure 2 and Figure 3. As we can see in Figure 2, the magnitude of the analytical signal for the $1.0 \mathrm{mg} \mathrm{L}^{-1}$ reference solution increases relative to the increased concentration of the $\left[(\mathrm{Cu}-\mathrm{Neo})_{2}\right]^{2+}$ solution up to $0.01 \mathrm{~mol} \mathrm{~L}^{-1}$ and after that the signal decreases. Given the results obtained, a concentration of $0.01 \mathrm{~mol} \mathrm{~L}^{-1}\left[(\mathrm{Cu}-\mathrm{NeO})_{2}\right]^{2+}$ was established.

The concentration of the $\mathrm{NaOH}$ solution might affect the sensibility of the procedure. The study was realized using the same parameters previously 
set and using the concentration of the $0.01 \mathrm{~mol} \mathrm{~L}^{-1}\left[(\mathrm{Cu}-\mathrm{Neo})_{2}\right]^{2+}$ solution, yielding the results shown in Figure 3. It is noted in this Figure, that increasing the concentration of the $\mathrm{NaOH}$ solution, heightens the magnitude of the analytical signal up to $0.05 \mathrm{~mol} \mathrm{~L}^{-1}$. Subsequently, there is a decrease in signal due to increased concentration of the $\mathrm{NaOH}$. This fact may be because the decomposition $\left[(\mathrm{Cu}-\mathrm{Neo})^{2}\right]^{2+}$ complex through the increasing concentration of $\mathrm{NaOH}$, forming the precipitate $\mathrm{Cu}(\mathrm{OH})_{2}\left(\mathrm{Ksp}=2.2 \times 10^{-20}\right)$. The precipitate formed can quickly saturate the cellulose nitrate membrane, making it useless. Thus, the concentration of $0.05 \mathrm{~mol} \mathrm{~L}^{-1} \mathrm{NaOH}$ solution was achieved.

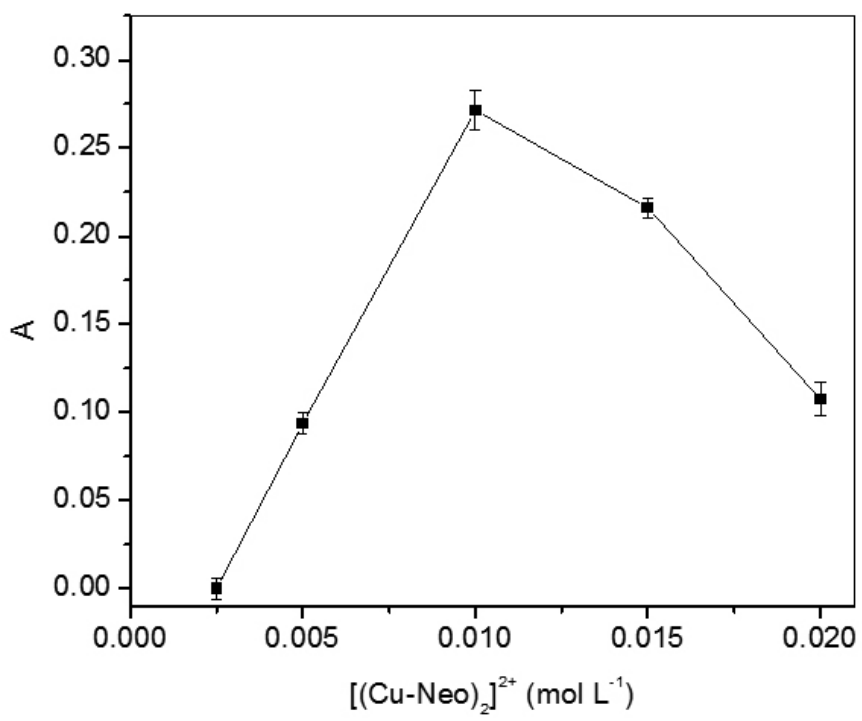

Figure 2. Effects concerning of the $\left[(\mathrm{Cu}-\mathrm{NeO})_{2}\right]^{2+}$ concentration.

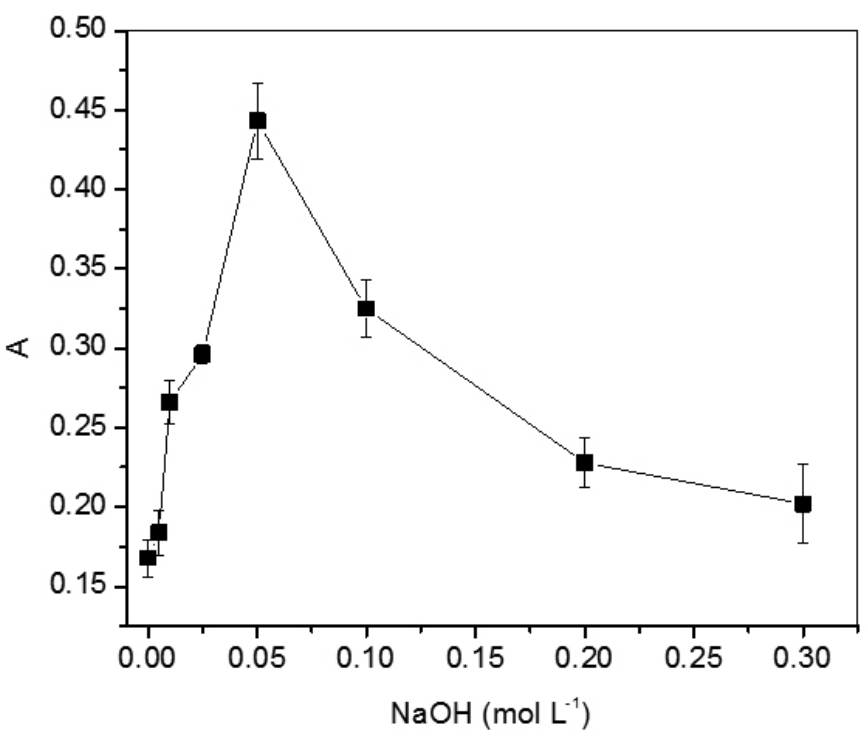

Figure 3. Effects concerning of the $\mathrm{NaOH}$ concentration.

\section{Effect of the temperature}

Temperature influences the reaction kinetics between the $\left[(\mathrm{Cu}-\mathrm{NeO})_{2}\right]^{2+}$ complex and reducing sugar. The effect of temperature on the magnitude of the analytical signal varying between 50 at $100^{\circ} \mathrm{C}$ was studied, maintaining the concentration at $1.0 \mathrm{~g} \mathrm{~L}^{-1}$ of RS. The magnitude of the analytical signal increases as the temperature is increased, up to a temperature of $85^{\circ} \mathrm{C}$. At temperatures above $85^{\circ} \mathrm{C}$, an onset of bubbles in the analytical course was noted. This hampered the stability of the flow system. Given this result, a temperature of $85^{\circ} \mathrm{C}$ was achieved.
Effect of the volumetric ratio $\mathrm{NaOH} / \mathrm{RS} /\left[(\mathrm{Cu}-\mathrm{Neo})_{]^{2+}}\right]^{2+}$

Because the volumetric ratio might affect the sensibility of the procedure, a set experiment was carried out in order to ascertain the optimum conditions. In this study, we used the univariate method.

At first, a study the volume of $\mathrm{NaOH}$ solution was carried out by switching ON/OFF micro-pumps $\mathrm{P}_{2}$ and $\mathrm{P}_{3}$ ten times and varying the micro-pumping $\mathrm{P}_{1}$ between four and twelve times for each sampling cycle, for a total of 10 cycles. Total slugs of the $\mathrm{NaOH}$ solutions with volumes of $160,320,400$ and 480 $\mu \mathrm{L}$ were inserted and the volumes of the sample and $\left[(\mathrm{Cu}-\mathrm{Neo})_{2}\right]^{2+}$ slugs were maintained at $400 \mu \mathrm{L}$, corresponding to a $0.4: 1: 1,0.8: 1: 1,1: 1: 1,1.2: 1: 1(\mathrm{v} / \mathrm{v})$ volumetric ratio $\mathrm{NaOH} / \mathrm{RS} /\left[(\mathrm{Cu}-\mathrm{NeO})_{2}\right]^{2+}$, respectively, yielding the results shown in Table 2. As can be seen, when the number of $\mathrm{NaOH}$ solution slugs was increased from 160 to $320 \mu \mathrm{L}$, the linear coefficient and the slope was improved, thereafter, with the increase of the volume of $\mathrm{NaOH}$ solution for 400 and $480 \mu \mathrm{L}$, there was a loss of linearity. Given the obtained results, a $\mathrm{NaOH}$ volume of the $320 \mu \mathrm{L}$, corresponding to 8 pulses of the micro-pump $\mathrm{P}_{1}$, was achieved.

Table 2: Effect of $\mathrm{NaOH}$ solution.

\begin{tabular}{|c|c|c|c|}
\hline $\begin{array}{c}\text { Pulses } \\
\mathrm{P}_{1}\end{array}$ & $\begin{array}{c}\mathrm{NaOH} \\
(\mu \mathrm{L})\end{array}$ & Equation & $\begin{array}{c}\text { Linear } \\
\text { coeficient }(\mathrm{R})\end{array}$ \\
\hline 4 & 160 & $y=\left(\begin{array}{r}0.2164 \pm 0.0406)+(0.3586 \pm \\
0.0330) x\end{array}\right.$ & 0.9875 \\
\hline 8 & 320 & $\begin{array}{r}y=(0.1715 \pm 0,0479)+(0.4444 \pm \\
0.0389) x\end{array}$ & 0.9887 \\
\hline 10 & 400 & $\begin{array}{r}y=(0.2681 \pm 0,0621)+(0.4178 \pm \\
0.0505) x\end{array}$ & 0.9788 \\
\hline 12 & 480 & $y=\left(\begin{array}{r}0.2470 \pm 0,0705)+(0.3477 \pm \\
0.0575) x\end{array}\right.$ & 0.9615 \\
\hline
\end{tabular}

To study the volume of the sample (RS) solution, we varied the total number of slugs of the sample solutions between 160 and $480 \mu \mathrm{L}$ maintaining the volume of $\mathrm{NaOH}$ solution and $\left[(\mathrm{Cu}-\mathrm{Neo})_{2}\right]^{2+}$ in 320 and $400 \mu \mathrm{L}$, respectively. The results are shown in Table 3. This table illustrates how an increase in the sample solution volume of 160 to $480 \mu \mathrm{L}$ results in a significant loss of linearity. For volumes less than $160 \mu \mathrm{L}$, corresponding to 4 pulses per sampling cycle, it was not possible to obtain a significant analytical response due to sensitivity of the proposed method. Given the results, a sample (RS) volume of the $160 \mu \mathrm{L}$, corresponding to 4 pulses of the micro-pump $\mathrm{P}_{2}$ for sampling cycle, was achieved.

Table 3: Effect of sample solution.

\begin{tabular}{|c|c|c|c|}
\hline $\begin{array}{c}\text { Pulses } \\
\mathrm{P}_{2}\end{array}$ & $\begin{array}{c}\text { Sample } \\
(\mu \mathrm{L})\end{array}$ & Equation & $\begin{array}{c}\text { Linear } \\
\text { coeficient }(\mathrm{R})\end{array}$ \\
\hline 4 & 160 & $\begin{array}{r}y=(0.2316 \pm 0.0318)+ \\
(0.2184 \pm 0.0147) x\end{array}$ & 0.9933 \\
\hline 8 & 320 & $\begin{array}{r}y=(0.2449 \pm 0.0532)+ \\
(0.2262 \pm 0.0269) x\end{array}$ & 0.9794 \\
\hline 10 & 400 & $\begin{array}{r}y=(0.3053 \pm 0.1186)+ \\
(0.2704 \pm 0.0558) x\end{array}$ & 0.9416 \\
\hline 12 & 480 & $\begin{array}{r}y=(0.3774 \pm 0,0872)+ \\
(0.1634 \pm 0.0440) x\end{array}$ & 0.8804 \\
\hline
\end{tabular}

Finally, the total volume of the $\left[(\mathrm{Cu}-\mathrm{Neo})_{2}\right]^{2+}$ solution was varied between 160 and $720 \mu \mathrm{L}$ (corresponding to variation from 4 to 18 pulses) of sample solutions per each sampling cycles and the $\mathrm{NaOH}$ and sample solution volumes were made constant at 320 and $160 \mu \mathrm{L}$, respectively, yielding the results shown in Table 4 . As can be seen, when the volume of the $\left[(\mathrm{Cu}-\mathrm{NeO})_{2}\right]^{2+}$ solution slugs was increased from 160 to $640 \mu \mathrm{L}$, the linear coefficient and the slope has improved, promoting a significant increase (about $40 \%$ ) in the sensitivity of the proposed method. The volume of $720 \mu \mathrm{L}$ showed loss of linearity and slope. This occurred possibly due to dilution of the sample in relation to the excess $\left[(\mathrm{Cu}-\mathrm{Neo})_{2}\right]^{2+}$ solution added. Thus, the volume of $640 \mu \mathrm{L}$, corresponding to 16 pulses of the micro-pump $\mathrm{P}_{3}$ for the sampling cycle was fixed to the sequence of studies. Therefore, the volumetric ratio between $\mathrm{NaOH}$, sample (RS) and $\left[(\mathrm{Cu}-\mathrm{Neo})_{2}\right]^{2+}$ solution was established as 2:1:4 $(\mathrm{v} / \mathrm{v} / \mathrm{v})$ after optimization of the proposed procedure. 
Table 4: Effect of $\left[(\mathrm{Cu}-\mathrm{Neo})_{2}\right]^{2+}$ complex solution.

\begin{tabular}{|c|c|c|c|}
\hline $\begin{array}{c}\text { Pulses } \\
\mathrm{P}_{3}\end{array}$ & $\begin{array}{c}\left.(\mathrm{Cu}-\mathrm{Neo})_{2}\right]^{2+} \\
(\mu \mathrm{L})\end{array}$ & $\begin{array}{c}\text { Linear } \\
\text { coeficient }(\mathrm{R})\end{array}$ \\
\hline 4 & 160 & $\begin{array}{r}y=(0.1589 \pm 0.1064) \\
+(0.0404 \pm 0.0552) x\end{array}$ & 0.4766 \\
\hline 8 & 320 & $\begin{array}{r}y=(0.1083 \pm 0.0444) \\
+(0.1932 \pm 00224) x\end{array}$ & 0.9742 \\
\hline 10 & 400 & $\begin{array}{l}y=(0,2316 \pm 0,0318) \\
+(0,2184 \pm 0,0147) x\end{array}$ & 0.9933 \\
\hline 12 & 480 & $\begin{array}{l}y=(0,1993 \pm 0,0612) \\
+(0,1861 \pm 0,0309) x\end{array}$ & 0.9610 \\
\hline 16 & 640 & $\begin{array}{l}y=(0,3597 \pm 0,0326) \\
+(0,3079 \pm 0,0169) x\end{array}$ & 0.9940 \\
\hline 18 & 720 & $\begin{array}{l}y=(0,2476 \pm 0,0497) \\
+(0,1959 \pm 0,0251) x\end{array}$ & 0.9762 \\
\hline
\end{tabular}

Effect of the sampling zone

Considering that the volume of the sample zone might affect the analytical signal and consequently sensitivity, the number of sampling cycles was varied from 2 to 20 cycles, corresponding to a sampling zone between 224 and 2240 $\mu \mathrm{L}$. As expected, the analytical signal was higher for a higher sampling zone volume. Nevertheless, when the number of sampling cycles was higher than 10 , no significant increase in the signal was observed, thus indicating that the system had attained a steady-state condition. Given this, the inserted volumes of $\mathrm{NaOH}$, sample (RS) and $\left[(\mathrm{Cu}-\mathrm{Neo})_{2}\right]^{2+}$ solutions of 320,160 and $640 \mu \mathrm{L}$ ( 8 pulses of $\mathrm{NaOH}, 4$ pulses of sample and 16 pulses of $\left.[\mathrm{Cu}-\mathrm{Neo})_{2}\right]^{2+}$ complex , respectively, were selected, which corresponds to 10 sampling cycles.

\section{Proposed procedure performance}

After performing the optimization of the proposed system for reducing sugar analysis, an analytical curve was plotted, shown in Figure 4. A linear response was observed between 0.25 and $4.0 \mathrm{~g} \mathrm{~L}^{-1}$ with the equation, $\mathrm{A}=(0.36$ $\pm 0.02)+(0.31 \pm 0.01) * \mathrm{C}(\mathrm{R}=0.9975, \mathrm{n}=6$, where $\mathrm{A}=$ absorbance and $\mathrm{C}=\mathrm{RS}$ concentration in $\left.\mathrm{g} \mathrm{L}^{-1}\right)$. The limit of detection ( $3 \sigma$ criterions) and quantification ( $10 \sigma$ criterions) were estimated at $0.03 \mathrm{~g} \mathrm{~L}^{-1}$ and $0.1 \mathrm{~g} \mathrm{~L}^{-1}$ respectively, sampling throughput of the 45 determinations per hour and effluent generation of 3.120 $\mathrm{mL}$ per determination were estimated. Under optimized conditions, the system showed a stable baseline and a satisfactory repeatability of analytical signals with a relative standard deviation of $2.6 \%(n=7)$ to consecutive insertion of the $2.0 \mathrm{~g} \mathrm{~L}^{-1} \mathrm{RS}$ solution. Given the above, it can be said that the proposed flow system for reducing sugar determination is feasible for analytical applications.

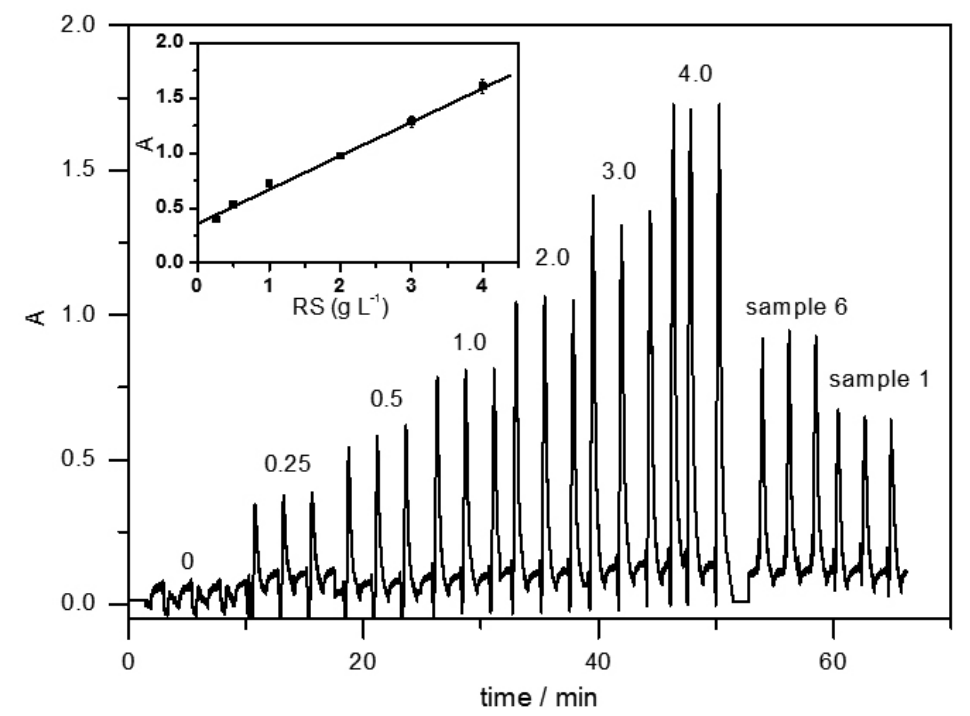

Figure 4. Transient signals obtained with the flow manifold in Fig.1.Numbers indicate RS concentrations in $\mathrm{g} \mathrm{L}^{-1}$ and letters indicate the consecutive insertion of the samples. The inset shows the corresponding analytical curve graph.

The results, summarized in Table 5, were presented in order to optimize the proposed system.

Table 5: Optimized parameters of the multicommuted flow system for determination of reducing sugars in wine.

\begin{tabular}{lrr}
\hline Parameter & \multicolumn{1}{c}{ Range } & Selected value \\
\hline $\mathrm{NaOH}$ concentration $\left(\mathrm{mol} \mathrm{L}^{-1}\right)$ & $0.005-0.3$ & 0.05 \\
{$\left[(\mathrm{Cu}-\mathrm{Neo})_{2}\right]^{2+}$ complex concentration $\left(\mathrm{mol} \mathrm{L}^{-1}\right)$} & $0.0025-0.05$ & 0.01 \\
Temperature $\left({ }^{\circ} \mathrm{C}\right)$ & $50-100$ & 80 \\
NaOH solution volumes $(\mu \mathrm{L})$ & $160-640$ & 320 \\
Sample solution volumes $(\mu \mathrm{L})$ & $160-640$ & 160 \\
{$\left[(\mathrm{Cu}-\mathrm{Neo})_{2}\right]^{2+}$ solution volumes $(\mu \mathrm{L})$} & $160-720$ & 640 \\
Sampling cycles & $2-20$ & 10 \\
\hline
\end{tabular}


To assess the performance of the proposed procedure, a comparison with methods described in the literature is summarized in Table 6 . The advantages of the proposed procedure include a lower detection limit, when compared to what has been described in the literature ${ }^{17,38}$ and less sample volume, waste generation and reagent consumption than what has been reported in standard methods, leading to a significant reduction in the costs of the analysis. These features indicate the feasibility of the proposed system.

Table 6: Analytical features of spectrophotometric procedures for determination of reducing sugars in wine.

\begin{tabular}{|c|c|c|c|c|c|}
\hline Parameters & $\begin{array}{c}\text { AOAC } \\
\text { ( Latimer Jr 2012) }\end{array}$ & $\begin{array}{l}\text { FIA }^{\mathrm{a}} \\
\text { (Maquieira et al., } \\
\text { 1987) }\end{array}$ & $\begin{array}{l}\text { FIA }^{\text {a }} \\
\text { (Peris-Tortajada et } \\
\text { al., 1992) }\end{array}$ & $\begin{array}{c}\text { SIA }^{\text {a }} \\
\text { (Araújo et al., } \\
\text { 2000) }\end{array}$ & $\begin{array}{l}\text { Proposed } \\
\text { method }^{\text {a }}\end{array}$ \\
\hline Linear Range $\left(\mathrm{g} \mathrm{L}^{-1}\right)$ & - & $0.05-1.0$ & $1.2-7.2$ & $2-25$ or $20-140$ & $0.25-4.0$ \\
\hline Detection limit $\left(\mathrm{g} \mathrm{L}^{-1}\right)$ & - & - & - & 1.2 or 11.2 & 0.03 \\
\hline R.S.D. $(\%)$ & - & 1.61 & - & 2.1 or 1.7 & 2.6 \\
\hline Sample volume consumption $(\mathrm{mL})^{\mathrm{b}}$ & 50 & 0.0453 & 0.143 & 0.120 or 0.340 & 0.160 \\
\hline Waste volume $(\mathrm{mL})^{\mathrm{b}}$ & 112 & 3.453 & 3.593 & 8.898 or 9.553 & 3.120 \\
\hline $\mathrm{NaOH}$ consumption $(\mathrm{mg})^{b}$ & 1000 & 40.32 & 34.50 & 4.95 & 0.160 \\
\hline Neocuproine (mg) ${ }^{\mathrm{b}}$ & - & 0.672 & 0.690 & 0.054 & 0.330 \\
\hline $\mathrm{CuSO}_{4}(\mathrm{mg})^{\mathrm{b}}$ & 692.78 & 0.336 & 0.345 & 0.027 & 0.128 \\
\hline Throughput $\left(\mathrm{h}^{-1}\right)$ & 1 & 50 & 40 & 18 or 14 & 45 \\
\hline
\end{tabular}

\section{Comparison results}

Once the optimal operational conditions were established, the determination of reducing sugar was performed in wine samples in order to test the functionality of the proposed procedure. The AOAC official method ${ }^{33}$ was used to test the accuracy of the assessment samples, yielding the results given Table 7.

Table 7: Comparative results obtained from determination of reducing sugars in wine samples.

\begin{tabular}{|c|c|c|c|}
\hline \multirow{2}{*}{ Sample } & \multirow{2}{*}{ Type of wine } & $\begin{array}{c}|c| \\
\text { AOAC } \\
\text { method }\end{array}$ & $\begin{array}{c}\text { Proposed } \\
\text { procedure }\end{array}$ \\
\cline { 3 - 4 } & dry red & $1.3 \pm 0.1$ & $1.2 \pm 0.1$ \\
\hline 1 & dry red & $8.4 \pm 0.3$ & $5.1 \pm 0.2$ \\
\hline 3 & dry red & $5.7 \pm 0.2$ & $4.3 \pm 0.3$ \\
\hline 4 & dry red & $3.5 \pm 0.2$ & $2.34 \pm 0.08$ \\
\hline 5 & dry red & $4.0 \pm 0.3$ & $2.9 \pm 0.1$ \\
\hline 6 & dry red & $1.8 \pm 0.2$ & $1.73 \pm 0.09$ \\
\hline 7 & medium dry & $13.7 \pm 0.1$ & $15.0 \pm 0.4$ \\
\hline 8 & medium sweet & $81.3 \pm 0.4$ & $81 \pm 6$ \\
\hline 9 & Liqueur & $110.5 \pm 0.7$ & $141 \pm 10$ \\
\hline 10 & Liqueur & $123 \pm 2$ & $156 \pm 2$ \\
\hline 11 & dry white & $3.0 \pm 0.2$ & $4.64 \pm 0.01$ \\
\hline
\end{tabular}

${ }^{a}$ Result average of three consecutive determinations \pm the corresponding standard deviation.

The paired t-test between results at the $95 \%$ confidence level was applied. The calculated value was $t=1.356$, while the theoretical value is $t=1.812$, indicating that there was no statistically significant difference between the results.

\section{CONCLUSIONS}

We consider the overall performance of the proposed system, including the equipment and setup of the control software, to be simple and easy to operate, with the advantage of eliminating the color of the wine through a dialysis cell, allowing sample introduction of dry red wine without prior dilution. In addition, we obtained economy of reagents and decrease in waste generation compared to the official method.

\section{ACKNOWLEDGMENTS}

The authors are grateful to FACEPE (PRONEX, Proc. APQ-03461.06/14), CNPq (Proc $n^{\circ}$ 204392/2014-4) and CAPES for financial support.

\section{REFERENCES}

1.- A.L. Galant, R.C. Kaufman, J.D. Wilson, Food Chem., 188, 149, (2015).

2-. J. Clayden, N. Greeves, S. Warren, P. Wothers, Organic Chemistry. Oxfor University Press, N.Y., 2001, pp.15-42.

3.- R.B. Boulton, V.L. Singleton, L.F. Bisson, R.E. Kunkee, Principles and practices of winemaking. Chapman \& Hall, N. Y., 1996, 585 p.

4.- OIV. Compendium of International Methods of Analysis of Wines and Musts. International Organisation of Vine and Wine, Paris, 2014, 504 p.

5.- K.S. Başkan, E. Tütem, E. Akyüz, S. Özen, R. Apak, Talanta, 147, 162, (2016).

6.- P. González, M. Knochen, M.K. Sasaki, E.A.G. Zagatto, Talanta, 143, 419, (2015).

7.- C.I.C. Silvestre, J.L.M. Santos, J.L.F.C. Lima, E.A.G. Zagatto, Anal. Chim. Acta, 652(1-2), 54, (2009).

8.- A.D. Batista, R.S. Amais, F.R.P. Rocha, Microchem. J., 124, 55, (2016).

9.- P.A.B. da Silva, G.C.S. de Souza, D.M.D.S. Leotério, M. F. Belian, W. E. Silva, A.P.S. Paim, A.F. Lavorante, J. Food Compos. Anal., 40, 177, (2015).

10.- L.G. Decnop-Weever, J.C. Kraak, Anal. Chim. Acta., 337(2), 125, (1997)

11.- M. Naghizadeh, M.A. Taher, M. Behzadi, F.M. Hassani, Chem. Eng. J., 281, 444, (2015)

12.- A.C. Pereira, F.R.P. Rocha, Anal. Methods, 5(8), 2104, (2013).

13.- A.C. Pereira, B.F. Reis, F.R.P. Rocha, Talanta, 131, 21, (2015).

14.- A.N. Ramdzan, P.J. Mornane, M.J. McCullough, W. Mazurek, S.D. Kolev, Anal. Chim. Acta, 786, 70, (2013).

15.- M.C. Yebra, M. Gallego, M. Valcárcel, Anal. Chim. Acta, 276(2), 385, (1993).

16.- M.D. Luque de Castro, J.L. Luque-Garcia, Anal. Letters, 33(6), 963, (2000).

17.- A.N. Araújo, J.L.F.C. Lima, A.O.S.S. Rangel, M.A. Segundo, Talanta, 52(1), 59, (2000)

18.- M.A. Feres, P.R. Fortes, E.A.G. Zagatto, J.L.M. Santos, J.L.F.C. Lima, Anal. Chim. Acta, 618(1), 1, (2008).

19.- G.C.S. de Souza, P.A. Bezerra da Silva, D.M.S. Leotério, A.P.S. Paim, A.F. Lavorante, Food Control, 46, 127, (2014).

20.- J.C.Miranda, M.Y. Kamogawa, B.F. Reis, Sens. Actuators B Chem., 207, $811,(2015)$.

21.- D.S.M. Ribeiro, C. Frigerio, J.L.M. Santos, J.A.V. Prior, Anal. Chim. Acta, 735, 69, (2012)

22.- D.L.Rocha, F.R.P. Rocha, Inter. Environ. Anal. Chem., 93(13), 1389, (2013) 
23.- W.R. Melchert, B.F. Reis, F.R.P. Rocha, Anal. Chim. Acta, 714, 8, (2012).

24.- A.C. Pereira, F.R.P. Rocha, Anal. Chim. Acta, 829, 28, (2014).

25.- A.L.D.Comitre, B.F. Reis, Anal. Chim. Acta, 479(2), 185, (2003).

26.- A.L.D.Comitre, B.F. Reis, Talanta, 65(4), 846, (2005).

27.- L. Li, L. Fang, Y. He, Instr. Sci. Technol., 31(3), 269, (2003)

28.- M.A. Sanchez, F.R.P. Rocha, Anal. Chim. Acta, 694(1-2), 95, (2011).

29.- S.M. Oliveira, T.I.M.S. Lopes, I.V. Tóth, A.O.S.S. Rangel, Talanta, 81(45), 1735, (2010).

30.- S.M. Oliveira, T.I.M.S. Lopes, I.V. Tóth, A.O.S.S. Rangel, J. Agric. Food Chem., 57(9), 3415, (2009).

31.- C.A. Tumang, M.C. Tomazzini, B.F. Reis, Anal. Sci., 19(12), 1683, (2003)

32.- D.M.S. Leotério, P.A.B. Silva, G.C.S. Souza, A.D.A. Alves, M.F. Belian,
A. Galembeck, A.F. Lavorante, Food Control, 57, 225, (2015).

33.- G.W. Latimer Jr, The Official Methods of Analysis of AOAC International, 19th Edition. Rockville, USA, 2012.

34.- F.P. Miller, F. Agnes, J.M. Vandome, J. McBrewster, Fick's Law of Diffusion. VDM Publishing, Saarbrücken, 2009, 82p

35.- J. Pawliszyn, Comprehensive Sampling and Sample Preparation: Analytical Techniques for Scientists. Academic Press, N.Y., 2012, 3200p.

36.- G. Lee, M.V. Rossi, N. Coichev, H.D. Moya, Food Chem., 126(2), 679, (2011)

37.- R. Ravichandran, M. Rajendran, D. Devapiriam, Food Chem. 146, 472 (2014).

38.- A. Maquieira, M.D. Luque de Castro, M. Valcarcel, Analyst, 112(11), $1569,(1987)$ 